\title{
Moral Imagination and Active Imagination: Searching in the Depths of the Psyche
}

\author{
Cécile Rozuel
}

\author{
Contact: \\ Dr. Cécile Rozuel \\ Institute for Socio-Management \\ Stirling Management School \\ University of Stirling \\ Stirling FK9 4LA, UK \\ Email: cecile.rozuel@stir.ac.uk
}

***Published in 2012 in the Journal of Management Development, 31(5), pp.488-501***

\begin{abstract}
Purpose - The paper highlights the parallels between the ethical concept of moral imagination and the psychoanalytical concept of active imagination. A model combining both concepts is then proposed and discussed. The paper argues that such synthesis is necessary to understand the process of moral deliberation as well as to foster more consistent moral choices in organisations.

Design/methodology/approach - The paper is conceptual, and builds upon relevant literature from the field of business ethics and analytical psychology.

Findings - Imagination is a thoroughly ambivalent concept, which can be used to pursue moral as well as immoral goals. Moral imagination is an important element influencing decision-making, but its quality depends on the state of balance of the psyche. A sound and effective moral imagination must be grounded in a healthy psyche, and needs the assistance of active imagination (or other similar activities) to achieve this. Such inner work is especially necessary for leaders to clarify their moral values and capabilities.
\end{abstract}

Research limitations/implications - The Active and Moral Imagination (AMI) model proposed has not been empirically tested; therefore its implications are tentative at this stage. The paper does not discuss in detail other psychological activities which may be complementary to active imagination.

Practical and social implications - Managers and leaders should reflect on their own unconscious so as to understand the deeper mechanisms influencing their decisions and behaviours.

Originality/value - An interdisciplinary approach to the role of imagination in ethics.

Paper type: Research paper

Keywords: moral imagination, active imagination, Jung, consciousness, self-reflection 


\section{Moral Imagination and Active Imagination: Searching in the Depths of the Psyche}

"...there is no cure and no improving of the world that does not begin with the individual himself." - Jung, 1928/1966, para.373

\section{Imagination and the Ethical Question(s)}

Amongst the many qualities attributed to a good leader, the ability to "build a vision" is essential to further the harmonious growth and development of the organisation, the followers and the leader her/himself (Fry, 2003). Charismatic, transactional, transformational or spiritual leaders all share an ability to inspire others through a common project more or less defined, more or less collective, more or less ambitious. We generally expect our leaders - in whichever context - to communicate a vision that carries values, triggers motivation, and sustains commitment. We expect responsible leaders to do so with an acute understanding of the ethical implications of each aspect of the vision. By all means, good leaders have to possess a rich imagination; good and responsible leaders have to possess a rich and moral imagination. Imagination has however been given only sparse attention, and many questions arise when examining the moral content, benefits and risks associated with imagination. My aim is to review some of these questions and provide, tentatively, elements of answers.

It is now widely acknowledged that imagination is an essential human capability for a harmonious psycho-social development. The faculty to imagine serves multiple purposes and actively helps us grow as an individual and as a member of society. Yet imagination is a rather ambiguous concept, which presents in and by itself some significant moral issues. This paper examines how imagination participates in the ethical deliberation process, and discusses how some of the moral issues attached to imagination as a decision-making tool can be addressed imaginatively. The structure of the paper is as follows: first, the ambiguity of imagination is introduced, before discussing the concept of moral imagination as a distinct process related to ethical decision-making. I then examine the psychoanalytical concept of active imagination as introduced by Carl G. Jung. The final part of the paper proposes and discusses an Active and Moral Imagination (AMI) model combining both concepts, with a particular focus on managerial and leadership implications.

\section{What is imagination?}

Imagination is a function of the mind. It involves both the ability to form and activate mental images without having been exposed to 'model-images', and the capacity to combine and rearrange images to create various scenes which differ from real-life occurrences (Bronckart, 1991). Imagination helps learning (one can better understand how something works if one can picture in their mind that particular mechanism or relation), healing (what traditional medicine generally labels 'placebo effect') and social relationships (empathy, the ability to 'put ourselves in someone else's shoes' enables us to perceive with greater sensitivity others' viewpoints and experiences). It produces dreams and daydreams, but also mental pictures or schemes, fantasies, phantasms, and deliriums (Jalley and Doron, 1991). It can alter our perception of reality to such an extent that it affects the body (e.g. psychosomatic diseases or, again, the 'placebo effect' prove that human psyche has an enormous influence on our whole 
being - see Jackson, 1990). Most importantly, imagination has the power to evoke feelings and emotions.

Being told that one has a good imagination is something most of us would take as a compliment: it implies that we are creative, artistic, visionaries. Imaginative people can think outside the box, they contribute something different from what less imaginative people can offer. Their inner world is rich, and they can draw from it to create a richer external reality. Of course, an imaginative disposition is not always cause for celebration. Extremely imaginative people can easily turn into eccentrics or lose themselves in their fantasies or phantasms. They may lose grip of reality and live only in their imagination. They may develop deliriums, psychosis or become pathological liars. These people would testify that imagination can be a curse. A good imagination is also problematic if it is directed towards fulfilling evil goals. Torturers can be highly imaginative in finding new ways to make their victim suffer. Ironically, the greater their empathetic disposition, the more evil they become for they can imagine the pain their victim will suffer and try to maximise it (Seabright and Schminke, 2002). Imagination, here, is definitely not an asset.

Imagination therefore needs to be qualified. It can have extremely positive effects on human disposition, as well as extremely distressing or concerning consequences. Imagination is essential in the moral process, but is also in itself a moral issue. What matters, ultimately, is what we do with it. Seabright and Schminke (2002) demonstrate how stages of moral reasoning can equally lead to moral or immoral behaviour. Building upon James Rest's fourcomponent model of moral reasoning, they explain how immoral behaviour can result from the very same model as that used to trigger moral behaviour whenever people either show a weakness of moral sensitivity and will, or deliberately aim to harm others. They suggest that imagination "enters into implementing immoral intentions" at least as much as moral intentions (Seabright and Schminke, 2002, p. 27). Immoral behaviour, they assert, is not just due to a failure to perceive the moral implications of one's action or a failure to reason appropriately about a moral dilemma; rather, it may result from "an active, even creative, process" whereby the individual deliberately seeks to harm the other (Seabright and Schminke, 2002, p. 28). The authors suggest that the key to understanding why and how imagination can turn evil lies in the self-image of the individual.

Imagination is a potentially valuable tool for enriching moral knowledge and moral deliberation, but its psychological foundations must be carefully examined. The concept of moral imagination encapsulates the view that a purely rational moral deliberation does not always produce the best moral decision. The capacity to assess a situation from other perspectives by means of imagination is necessary to avoid involuntary moral blindness. Yet moral imagination is itself constrained by deeper psychological processes. Individuals who trust their imaginative ability to respond more appropriately to an ethical dilemma may unwittingly fall prey to unconscious desires that perturb or distort their moral assessment. For the sake of preserving their "desired self" and avoid embodying their "feared self" (Markus and Nurius, 1986), some may embrace thoroughly unethical actions, and yet believe they are right or justified in doing so. In simple terms, moral imagination works best on a sane ground. What then shall we do to ensure our psyche does not interfere negatively with our moral deliberation process? The best and most demanding answer is to know oneself. Imagination again can be of assistance to achieve that goal. The concept of active imagination, developed by Carl G. Jung, proves useful in guiding our self-exploration: active imagination is groundwork for moral imagination. 


\section{Moral Imagination: Principle and Purposes}

The moral dimension and moral function of imagination has been noted by many, including Kant albeit in a rather sibylline way (Johnson, 1985; see also Werhane's review, 1999, p.90 onwards). As a specific construct, moral imagination can be traced back to the philosophies of David Hume and Adam Smith who valued sympathy as a motive for moral behaviour (Johnson, 1993; Moberg and Seabright, 2000). Sympathy, and its close cousin empathy, are generally understood in terms of perspective-taking, whereby one imagines what one would feel like if one were to be in someone else's position (Magai and McFadden, 1995). Smith's first paragraphs in the Theory of Moral Sentiments discuss sympathy as a natural human disposition. He explains that: "pity and compassion" are "the source of our fellow-feeling for the misery of others" since "it is by changing places in fancy with the sufferer, that we come either to conceive or to be affected by what he feels" (Smith, 1790/2000, Part I, Chapter I).

That Smith talks about sympathy and not simply perspective-taking is important, for one's character warrants greater or lesser moral effects of one's perceptive-taking. One can recognise that someone is in pain, understand the effect of pain for the individual, and even feel the pain through an imaginative empathetic connection with the other; yet there is no guarantee that one will do something to stop the pain from being inflicted onto the other, whether this is in their power or not. In order to lead to moral action, perspective-taking within the context of empathy or sympathy "requires integrity, profound self-knowledge, and an ability to effect the results one is responsible for" (Moberg and Seabright, 2000, p. 855). In other words, sensitivity and imagination are not enough to guarantee a moral outcome; rather the quality of the self strongly contributes to determining the latter.

Moral imagination does not merely relate to empathetic qualities. Kekes (2006), for example, acknowledges the role self-reflection plays in moral imagination, although he cautions that this should not be a merely rational exercise. His view of moral imagination is agent-centred and eudaimonistic, and aims at enlarging the individual's life through an understanding of the available social and personal possibilities so as to lead a responsible and fulfilling life (Kekes, 2006). The deliberation process is psychologically complex as it involves "cognitive, emotive, and volitional components, in addition to the what-it-would-be-like form of imaginative one" (Kekes, 2006, p. 23).

Moberg and Seabright (2000) adopt a more pragmatic definition of moral imagination. They review how moral imagination influences, either positively or negatively, each of the four stages of moral reasoning identified by James Rest, namely moral sensitivity, moral judgement, moral intention and moral behaviour. Doing so, they expand on Patricia Werhane's discussion on how moral imagination can help improve ethical behaviour in organisations. Werhane's work on moral imagination has had a strong influence on current research in the area of ethics, imagination and organisations; therefore I shall adopt her definition. Others have contributed to developing the concept of moral imagination, especially as narrative construction, such as John Dewey or Martha Nussbaum. Yet, Werhane's specific interest in enhancing decision-making through imagination makes her account particularly relevant to leadership development. In her seminal book Moral Imagination and Management Decision Making (1999, p. 93), she defines moral imagination as follows: 
"Moral imagination is the ability in particular circumstances to discover and evaluate possibilities not merely determined by that circumstance, or limited by its operative mental models, or merely framed by a set of rules or rule-governed concerns. In managerial decision-making, moral imagination entails perceiving norms, social roles, and relationships entwined in any situation."

Werhane (1999) refers to the 1950 Japanese movie Rashōmon by Akira Kurosawa to illustrate the benefits of being morally imaginative. The same event can be perceived very differently by its various actors and observers. Each person's perception is influenced by one's narratives, conceptual schemes and/or mental models. Our culture, the social and institutional groups we belong to, our own personal motives all shape our experiences, so that people rarely see the same scene, even though they all witness the same scene. Yet, the underlying assumption is that others see what I see, and I see what others see. Therefore we fall prey to inherent and inevitable biases by failing to realise that others may have a very different reading of life events since they operate within a different narrative and with a different mental model. In brief, others do not necessarily see what I see, and I do not always see what others see.

Morally speaking, the implications of a "Rashōmon effect" are tremendous. A manager working for a multinational will have developed a certain mental model that incorporates the company's objectives, the organisational culture, the formal and informal expectations attached to his position. This mental model enables him to function efficiently at his job, a fact well described by Gioia (1992) as "operating with scripts". Whether he realises it or not, our manager's perception of the business environment is influenced and constrained by his mental model: he sees what the model enables him to see; he does not see what the model does not account for. As a consequence, he may make a perfectly moral decision (in his view) and yet fails to see that this decision will harm many stakeholders once it is implemented. Because he operates under a certain mental model, some elements are likely to be automatically discarded even though they are relevant to the situation. The obvious lack of moral imagination leads to potentially immoral behaviour, but does not imply that the harm is intentional. People who lack moral imagination are morally accountable not because of something they do, but because of something they do not do: they do not question their mental models, they do not think of alternative perspectives on the issue at stake, they do not step back and observe themselves thinking. The mental models act as "filters" for our perception of external reality and facts (Werhane, 1999, p. 49).

Moral imagination thus enables one to overcome unintentional harm caused by a lack of selfawareness. The morally imaginative manager will endeavour to identify his preconceptions and biases, the organisational and social schemes that influence him, and then imagine what he would think of the situation if he were in someone else's position, influenced by a different set of organisational and social schemes. He might realise that there are other valid interpretations of the issue at stake. More importantly, he might identify options and solutions which provide a more beneficial outcome for all stakeholders, but which were unconceivable under his previously restricted perspective. 


\section{Practical implications for decision-making}

The advantages of moral imagination for decision-making are exciting. According to Werhane (1999, p. 93): "Developing moral imagination involves heightened awareness of contextual moral dilemmas and their mental models, the ability to envision and evaluate new mental models that create new possibilities, and the capability to reframe the dilemma and create new solutions in ways that are novel, economically viable, and morally justifiable." Moberg and Seabright (2000) suggest several benefits to moral imagination: enlarging one's ability to identify possible courses of action by transcending scripts and common moral boundaries; developing moral mindfulness; fine-tuning one's relation to moral rules to determine when they should be universally binding and when they should allow for flexibility; elaborating and assessing "possible selves" (Markus and Nurius, 1986) that reinforce intentions through both social and self-sanctions and motivations.

Roca (2010) argues that moral imagination stimulates moral intuition (to develop a wider range of possible scenarios), fine-tunes moral judgement to align with one's moral identity, and allows one to envision new ways of approaching an issue through a "critical creativity". Applying the concept to socially "dirty jobs", Roca (2010) proposes that organisations can induce greater moral imagination by encouraging the expression of individuality and critical thinking, by building up knowledge of one's community to understand 'others', and reassessing the content of job design. She also notices that narratives are useful in enhancing awareness of complex issues.

Moral imagination however is not a panacea, especially because a good imagination can also lead to immoral behaviour. Werhane (1999) acknowledges that moral imagination is a necessary but not sufficient component of ethical decision-making. It is a thoroughly dynamic process which purports to challenge and question rather than to provide ready-made solutions to ethical dilemma (Werhane, 1999, p. 126). More worrying are instances where imagination is corrupted. In such cases, imagination may lead to an even more harmful behaviour than a lack of imagination. Seabright and Schminke (2002, p. 24) identify various outcomes: "Moral imagination humanizes and includes the other; a lack of imagination objectifies and indirectly excludes the other; and immoral imagination demonizes and actively excludes the other." It is therefore important to dig deeper into the individual psyche and assess the context in which imagination works. If the individual's sense of self is unclear or pervaded by dark thoughts, s/he is much more likely to display a weaker moral imagination.

McVea's (2009) comparative study of experienced entrepreneurs and MBA students found that one's perceived moral identity strongly influenced the quality and scope of their moral imagination, which contrasts with Caldwell and Moberg's (2007) study findings. McVea (2009, p. 495) observed that whilst entrepreneurs adopted a sense of self as "a fully integrated human-being making a personal decision", MBA students overwhelmingly reacted as "a detached professional carrying out a role". Consequently, MBA students demonstrated a much narrower apprehension of the ethical components of the issue, and were more likely to focus on profit alone to make their decisions. McVea (2009) suggests that entrepreneurs' conscious perception and endorsement of self-identity is crucial in developing both ethical and technical skills. Exploring the ins and outs of one's sense of self remains an essential task for all individuals. 


\section{Active Imagination: Diving into the Unconscious}

Carl G. Jung occupies a peculiar place in the psychological field. Over his life-span, he explored a great variety of fields with the aim to discover the dynamics of the psyche. Most interestingly, Jung tested on himself the creative methods he later wrote about, which are now fully-fledged features of what has become known as analytical psychology. Jung acknowledged that what works for one may not work for another, because we are all individuals and experience things in different ways. One has to feel whether such or such technique is right for him or her. We each have our own sensitivity, our own experience of the struggle with unconscious contents. Exploration of the inner world is highly personal, intimate, yet it opens doors to a renewed connection with our external environment. The process and outcome are thus deeply personal, but the themes and the overarching principles at play are, for their part, collective.

The outcome of the process is a unifying of the psyche, a coming-togetherness of one's consciousness with the many unconscious forces culminating in an alignment of the ego with the archetypal self. Jung called this 'individuation'. Not everyone can become individuated, for this is a life-long and often painful process; however everyone can - and should - strive towards greater integration of the unconscious with consciousness so as to avoid potential psychological imbalances at some point or another. Besides, the concept of individuation possesses interesting moral value for it brings about a sense of balance, authenticity, integrity and in-depth connection with the social world (Jung, 1928/1966, para.373; Rozuel, 2010a).

For those willing to take the challenge, generally through an invitation or an imperious summons by the unconscious, Jung advised many sessions of self-reflection and intuitive creative expressions. Active imagination is one of the techniques Jung devised in the early 1910 s, although he expanded it over the years and eventually named it 'active imagination' (Chodorow, 1997, p. 3). This was a time which Jung described in his memoirs as filled with "inner uncertainty" and "disorientation" marked by his parting with Freud (Jung, 1963/1995, p. 194). One of his first experiences of active imagination consisted in him rediscovering the pleasure of building houses with stones, on the lake shore nearby his house. The purpose of such activity was to let the unconscious figures convey to consciousness what they had to convey, whilst enabling the ego to fully participate in deciphering the message (Jung, 1963/1995, pp. 197-99).

\section{Practicing active imagination}

Active imagination can take many different forms, but the 'active' part implies an actual creation. It differs from daydreaming or passive imagination, because in those cases either the ego is too present, controlling the fantasy, or not present enough, hence failing to notice the important symbolic clues. Depending on one's preference (or on the unconscious' preference), active imagination can find expression in writing, drawing, painting, sculpting, sandplay, dancing, creating music or acting. It is usually recommended though that we use a medium for which we are not naturally gifted, so as not to turn the exercise into a conscious artistic creation. Indeed, the creations ought not to be considered for their artistic value; rather their worth lies in what they express, what they reveal about the ongoing process of transformation within the individual's psyche. Bluntly, one could say they represent the road signs telling one where one is, though often in a symbolic manner. If one fails to work out the 
meaning of the road signs by oneself (or with the help of a therapist versed in symbols), then one may be stuck or lost for a while. The full participation of the ego gives meaning to the quest into the unconscious for it acts as "a torchlight thrown onto the unconscious [...which] brings corresponding and often remarkable co-operation from the psychic hinterland." (Weaver, 1973).

The process of active imagination generally starts with an image. This can be a dream, a recurring fantasy or, more elusively, a mood that one tries to picture. Jung (1955/1970, para.706) describes what comes next:

"You can then fix this image in the mind by concentrating your attention. Usually it will alter, as the mere fact of contemplating it animates it. The alterations must be carefully noted down all the time, for they reflect the psychic processes in the unconscious background, which appear in the form of images consisting of conscious memory material. In this way conscious and unconscious are united, just as a waterfall connects above and below. A chain of fantasy ideas develops and gradually takes on a dramatic character: the passive process becomes an action. [...] The piece that is being played does not want merely to be watched impartially, it wants to compel [the observer's] participation. [...] This process of coming to terms with the Other in us is well worth while, because in this way we get to know aspects of our nature which we would not allow anybody else to show us and which we ourselves would never have admitted."

Active imagination thus goes beyond conscious fantasy as it allows images to "have a life of their own" without the rational ego censoring or interfering with the process (Jung 1935/1977, para.397). The ego is at first a mere observer, watching as the unconscious unfolds and more importantly differentiating itself from the various voices or characters being introduced. Later on, however, the ego shall take an active part and question the plot, request clarifications, ask for more in an attempt to unveil the actual meaning of the work, and to bring insights into one's life (Jung, 1963/1995 pp. 207-12). Active imagination was developed as a psychoanalytical tool, and the presence and guidance of an analyst may be at once necessary. Yet Jung cited several cases where patients had discovered active imagination on their own, because they were ready to work at that level of self-exploration (Chodorow, 1997, p. 16). Ultimately, the value of active imagination depends on the individual's needs and readiness to engage. It is a loose method that accompanies the individual throughout her/his quest for unity and self-meaning. As such, it is not merely a psychoanalytical tool; it is a life-meaning tool.

In the final part of the paper, I argue that active imagination can be envisioned as groundwork for a more consistent, authentic and actually moral imagination. If an individual uses moral imagination without further work on the unconscious, the effectiveness of moral imagination will eventually run dry because of unacknowledged tensions blocking the development and maturity of the ego, trigger of our personality. The real richness of our personality, our potential as human beings lies in the depths of the unconscious. Without a substantial and conscious effort to uncover our unconscious, our conscious life will ever be limited (Jung, 1935/1977, para.398). 


\section{Active Imagination as Groundwork for Moral Imagination: The AMI Model}

Morality is ultimately a matter of personal choice. The individual's psyche plays an important part in the decision-making process. One's sense of who one is determines the scope of one's perceived moral choices and possible moral actions (Markus and Nurius, 1984). Besides, "...people choose the moral alternative because of the very personal stakes that are at issue; the choice signifies who they are and who they appear to be to others." (Moberg and Seabright, 2000, p. 867). In Jungian terms, one's choice in moral or immoral imagination is partly influenced by one's ego attachment to the persona. The ego must first disassociate from the persona for the individual to truly know what $\mathrm{s} / \mathrm{he}$ stands for in moral terms.

I propose that active imagination precedes and nurtures our ability to use moral imagination. Active imagination offers significant insights into one's unconscious, and contributes to a deeper knowledge of self. It does not constitute the very first step of self-exploration, nor is it suited for everyone. Yet, in so far as active imagination is a very flexible technique with very personal results, one can speculate it offers a valuable alternative to other self-enquiry methods. If enough preparatory work has been done to disengage the ego from an identification with the persona (the social roles we embrace) whilst carefully enhancing awareness of the conscious-unconscious connections (Rozuel, 2010b), then active imagination can truly make a difference in asserting individual moral values that are close to the self and respectful of the community.

Moberg and Seabright (2000, p. 869) add that: "Moral intentions depend upon the existence, activation, and elaboration of a future moral self. To the extent that such a self does not exist, or is out of mind, then moral intentions are, in a sense, 'unimaginable'." I would rephrase that statement in the following terms: moral intentions depend upon the awareness of one's self and its moral content. To the extent that one lacks consciousness of the self, whether by means of ego-persona identification, shadow-influence or other blinding archetypal projection, then moral intentions lack a clear moral direction. An individual in that situation has seemingly surrendered her/his moral agency and autonomy to an external authority (out of fear or spirit of camaraderie), but may not even be conscious of having done so. The subsequent moral analysis of an issue and of the individual's own conduct is most likely flawed because s/he is subjected to collective dictates. S/he does not act as her/himself; rather $\mathrm{s} / \mathrm{he}$ acts as an undifferentiated pawn (Terestchenko, 2007). The problem thus may not be the absence of a future moral self; rather the self is present but disconnected from the individual's consciousness. The effects upon one's morality may be similar, leading to immoral actions or amoral perspectives on issues. Yet the ways of addressing the problem differ: the moral psychological challenge is not to construct a moral self (which can very well go against the individual's inner personality if it is too enmeshed in external social norms) but to unveil one's self in order to access a more authentic moral knowledge. Being a consciously, actively more authentic-to-self individual would hopefully help contravene any collective psychological manipulation of the organisational members. The individual, having sorted out some of her/his psychological tensions, is free to connect with the world at a more fundamental level:

"In this way there arises a consciousness which is no longer imprisoned in the petty, oversensitive, personal world of the ego, but participates freely in the wider world of objective interests. This widened consciousness is no longer that touchy, 
egotistical bundle of personal wishes, fears, hopes, and ambitions which always has to be compensated or corrected by unconscious counter-tendencies [Note: thereby creating complexes]; instead, it is a function of relationship to the world of objects, bringing the individual into absolute, binding, and indissoluble communion with the world at large." Jung (1928/1966, para.275).

Figure 1 represents how active imagination contributes to reinforcing moral imagination for the individual to connect more authentically with others. The ego is the centre of our consciousness, that which leads our life. According to Jung's personality types (1921/1971), the ego is influenced by four main functions: the 'thinking' function activates our rationality (what we think, rationally analyse); the 'feeling' function filters and assesses our emotions (what we feel); the 'sensing' function works alongside the physical body (what we physically experience, act and react to); whilst the 'intuiting' function resonates with the 'inner voice' or 'gut feeling' which for most is indefinable but nonetheless meaningful. The ego is at the forefront of our personality but is directly influenced by the unconscious. The collective part of the unconscious contains archetypes and complexes. Archetypes are primordial images that picture certain character traits and mould our personality in a unique yet universal manner. The first archetype we encounter is generally the Shadow, the dark, underlying psychic energy. Complexes reflect the influence of an archetype on some personal content, and consist in those mechanisms, those feelings, those ideas that lie on the verge of consciousness and surreptitiously influence our behaviour in either positive or negative way until we acknowledge their role and identify the archetype they represent. The self is the central archetype and symbolizes unity and wholeness. It represents our true potential. Morally, the self informs ethical conscience, a more authentic form of conscience as contrasted with the social norms that traditionally shape our value system (Rozuel, 2010a). Manifestations of ethical conscience is more akin to intuition than reason, as Jung describes it as the "voice of God" (1958/1970, para.840-1). 


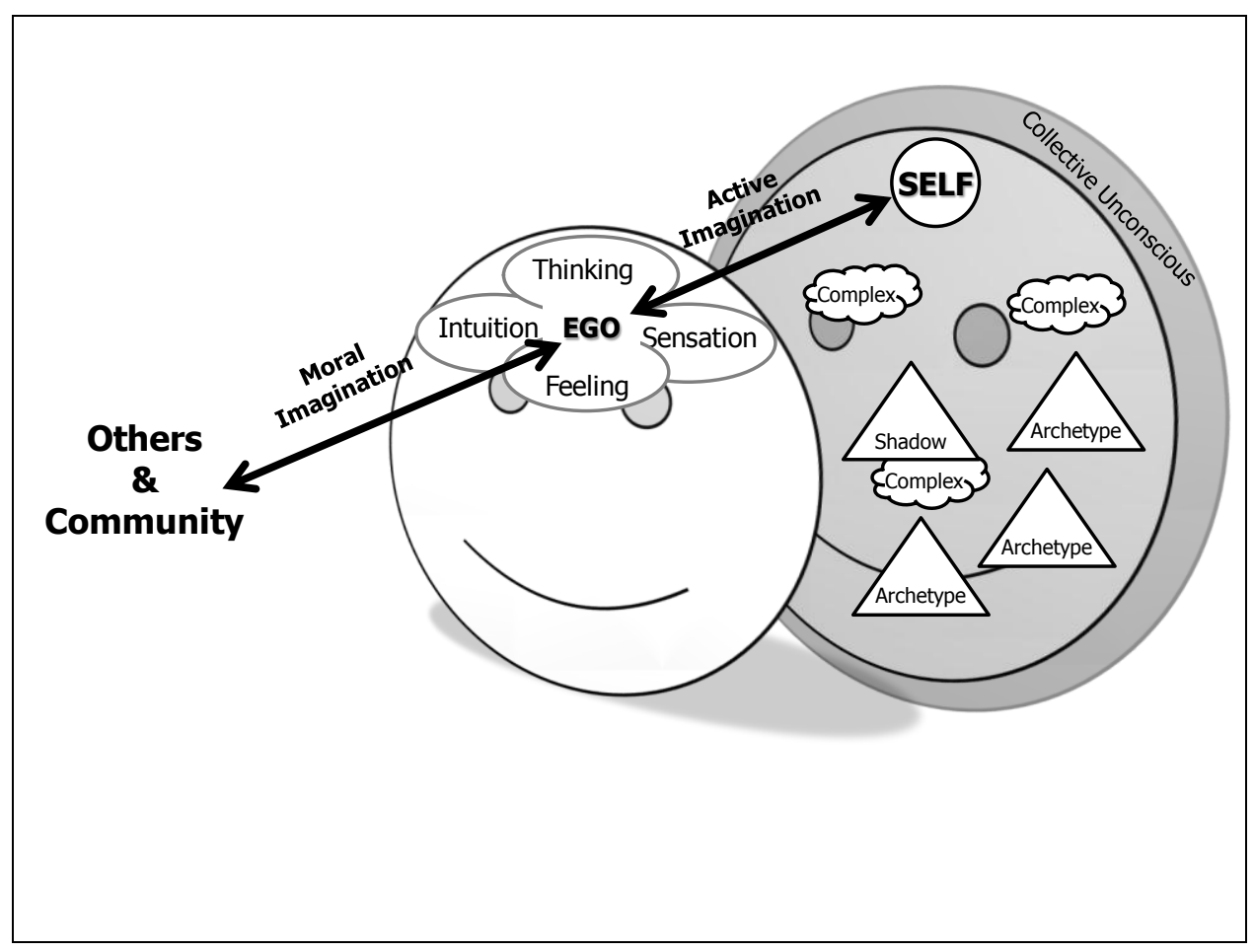

In this framework, active imagination consists in the ego exploring the unconscious without attempting to control it. The ego should not take over the imaginative work, but it should nonetheless be fully alert and participate in the meaning-making process. As a result of that groundwork, the ego has a more acute perception of the subjective forces that influence it, and is better prepared to act as an autonomous agent. Greater awareness of one's unconscious life affects the ego's relation with the external world on all levels. The ego understands better the meaning and dynamics of one's emotions, which are often linked to physical sensations; the ego also establishes a clearer connection to intuition and knows, rationally, how to use these various insights and influences to cope more effectively with life's events. Consequently, the newly authentic ego, more aligned with the self, can make better use of moral imagination and develops in turn a more genuine empathy and more effective relationships with others. This results in a moral behaviour consistent with one's core values and aspirations.

\section{Implications and Conclusion}

Overall, active imagination establishes a fruitful dialogue (or multilogue) between the self, the archetypes, and ego-consciousness. It clarifies the map of the psyche, brings greater selfunderstanding and self-mastery. Moral imagination, on the other hand, establishes a more enduring link between ego and others, thus building and widening its scope of possibilities through the active imagination dialogue.

One's psychological type might raise different issues for the exercise of moral and active imagination. As previously mentioned, Jung identified four main functions that help classify 
the various perspectives taken by individuals, alongside the opposite attitudes of introversion and extraversion. One is either an introvert (that is one's libido is oriented towards the inner world, the subjective psychic activities) or an extravert (one's libido is oriented towards the external, objective environment), and both attitudes are mutually exclusive (Hall and Nordby, 1973/1999). In contrast, everyone possesses all four functions, albeit one is generally dominant, with another function acting as auxiliary, whilst the other two remain underdeveloped. Thinking and feeling are called rational or judgement functions because they purport to classify, evaluate or connect 'data'. Sensing and intuiting are irrational functions in so far as they do not operate any such evaluation - they just work with whatever comes, indiscriminately (Jung, 1921/1971). As per the law of opposites and compensation dear to Jung, the two rational functions stand in opposition to one another, and the irrational functions equally oppose one another. Consequently, if one's dominant function is thinking, one's auxiliary function cannot be feeling; if one is mainly a sensing type, the auxiliary function will not be intuition (Jung, 1921/1971).

The important factor relating to the AMI connection is twofold: firstly, the under-developed functions generally find a compensatory expression in the unconscious which in turn can affect one's behaviour significantly. If one lacks awareness of one's compensatory surges, one may fall into ethical traps more frequently as one's sense of unity and mastery is compromised. Secondly, each function connects with imagination in different ways (e.g. people whose dominant function is rational - thinking or feeling - might find it harder to open up to active imagination than 'non-rational' types, especially if they are extraverted). Depending on which function is dominant in an individual, s/he would work with moral imagination in different ways:

- Thinking as dominant function: from a moral perspective, it challenges the individual to identify her/his mental models and to assess and possibly change or discard them even if it does not appear 'logical'.

- Feeling as dominant function: as the other rational function, feeling processes emotional responses in a structured manner. The moral challenge would consist in opening up to more intuitive connection to others via empathy, whilst maintaining one's integrity as self.

- Sensing as dominant function: it reflects what we can do in our time and place according to what we sense through a physical connection to the situation, both actual and imaginary. The challenge may be to translate sensory information into morally meaningful values.

- Intuiting as dominant function: this includes our gut feeling, the guidance of unscripted calls, spontaneous and unrestricted by existing, often external guidelines. The moral challenge is to channel intuitive insights into cohesive actions.

These links are tentative and more work is needed to refine the eventual correspondences between Jung's psychological types and moral imagination. They nonetheless suggest that self-knowledge is essential in any discussion of moral behaviour. Looking inwardly, irrelevant of one's extraverted or introverted tendencies, is a necessary step towards making sense of one's behaviour, motivations and aspirations. Yet, most organisations freeze at the thought of letting their employees explore their psyche. Jung wrote in the 1950s that activities such as meditation and contemplation, which entice active imagination, "have a bad reputation in the West. They are regarded as a particularly reprehensible form of idleness or as pathological narcissism. No one has time for self-knowledge or believes that it could serve 
any sensible purpose. Also, one knows in advance that it is not worth the trouble to know oneself, for any fool can know what he is." (1955/1970, para.709).

Even though people are increasingly more open to inward exploration nowadays, the vast majority of today's company managers and leaders would be at best sceptical, at worst depreciative of the value of self-reflection. They too would sanction this as a waste of time which translates as a waste of resources and a waste of money. The paper has argued, however, that this would be a mistake with serious moral implications. Activities such as active imagination are necessary to help the individual find her/himself, to understand the inner conflicts s/he is affected by, and to be more readily capable of handling a moral dilemma with care and consistency. Organisations, by all means, are affected by their members' psyche. The more the members' unconscious is silenced and repressed, the greater the tension within each individual and the more harmful the long-term consequences for the individual and her/his environment. It is in organisations' best interests to make room for their employees' self-explorations - these would not necessarily take place in the office but should at least be acknowledged as part of one's developmental process at work. Werhane (2002) reminds us that organisations are systems and that the practice of moral imagination must involve "systems thinking". This means that the process of moral deliberation, with its affective and cognitive components, must also assess the interrelations of actors, networks and the "systemic arrangements" that influence, define or constrain the moral issue(s) at stake. Yet she cannot but conclude that "each of us is responsible for examining, evaluating, critiquing and finding means to change organizations and systems in which we find ourselves." (Werhane, 2002, p. 41). Terestchenko (2007, p. 293) concurs that: "The responsibility lies with each and every one of us to guard oneself against our own tendency to obey so as to be ready to act in accordance with our principles when a 'destructive' authority commands that we leave these principles aside." Leaders thus have a key role to play: they can be exemplars, they can inspire, they can support, or they can defend the individual's right to be her/himself whilst negotiating the boundaries of the organisational collective. More importantly, they have to walk the self-discovery path themselves to nurture their integrity.

Leaders must have a sense of direction, especially when the collective organisation experiences a moral crisis. Moral imagination as the ability to envision the situation in different ways is essential. Yet equally essential is for the leader to have a fair consciousness of her/his own shadow, her/his own fears and dreams of greatness, for these can alter her/his perceptive skills. Unconscious forces, often through complexes, can overwhelm us in such a way that we do not realise that we already interpret the situation through the complex; rather, we believe that we are as objective as one can be. Within organisations, individuals interact on a regular basis and the potential for projection of one's own shadow onto others is high. Relationships can go awry and jeopardize individual and organisational development. This is why moral imagination as a stand-alone tool to decision-making is not sufficient: without a solid, lengthy observation and analysis of one's psyche, moral imagination is only as strong as a tree without roots. If a complex arises, the tree can fall and moral imagination cannot function properly. One must know who one is in order to determine where one must go, and organisational leaders have an acute responsibility in this domain. 


\section{References}

Bronckart, J.-P. (1991), "Imagination", in Doron, R. and Parot, F. (Eds.), Dictionnaire de Psychologie, Presses Universitaires de France, Paris, p. 366.

Caldwell, D.F. and Moberg, D. (2007), "An Exploratory Investigation of the Effect of Ethical Culture in Activating Moral Imagination”, Journal of Business Ethics, Vol. 73 No. 2, pp. 193-204.

Chodorow, J. (Ed.) (1997), Jung on Active Imagination, Princeton University Press, Princeton, NJ.

Fry, L.W. (2003), "Toward a Theory of Spiritual Leadership", The Leadership Quarterly, Vol. 14 No. 6, pp. 693-727.

Gioia, D.A. (1992), "Pinto Fires and Personal Ethics: A Script Analysis of Missed Opportunities", Journal of Business Ethics, Vol. 11 No.5/6, pp. 379-389.

Hall, C.S. and Nordby, V.J. (1973/1999), A Primer in Jungian Psychology, Meridian/Penguin, New York, NY.

Jackson, S.W. (1990), “The Imagination and Psychological Healing”, Journal of the History of the Behavioral Sciences, Vol. 26 No. 4, pp. 345-358.

Jalley, E. and Doron, R. (1991), "Imaginaire”, in Doron, R. and Parot, F. (Eds.), Dictionnaire de Psychologie, Presses Universitaires de France, Paris, p. 365.

Johnson, M. (1985), "Imagination in Moral Judgment", Philosophy and Phenomenological Research, Vol. 46 No. 2, pp. 265-280.

Johnson, M. (1993), Moral Imagination, The University of Chicago Press, Chicago, IL.

Jung, C.G. (1921/1971), Psychological Types, Collected Works Vol.6, Routledge \& Kegan Paul, London.

Jung, C.G. (1928/1966), "The Relations between the Ego and the Unconscious", in Two Essays on Analytical Psychology, Collected Works Vol.7 ( $2^{\text {nd }}$ ed.), Princeton University Press, Princeton, NJ, pp. 122-241.

Jung, C.G. (1935/1977), "The Tavistock Lectures", in The Symbolic Life, Collected Works Vol.18, Routledge \& Kegan Paul, London, pp. 5-182.

Jung, C.G. (1955/1970), Mysterium Coniunctionis, Collected Works Vol.14 (2 ${ }^{\text {nd }}$ ed.), Princeton University Press, Princeton, NJ.

Jung, C.G. (1958/1970), "A Psychological View of Conscience", in Civilization in Transition, Collected Works Vol.10 ( $2^{\text {nd }}$ ed.), Princeton University Press, Princeton, NJ, pp. 437-455. 
Jung, C.G. (1963/1995), Memories, Dreams, Reflections, Fontana Press/HarperCollins, London.

Kekes, J. (2006), The Enlargement of Life: Moral Imagination at Work, Cornell University Press, Ithaca, NY.

Magai, C. and McFadden, S.H. (1995), The Role of Emotions in Social and Personality Development: History, Theory, Research, Plenum Press, New York, NY.

Markus, H. and Nurius, P. (1986), "Possible Selves", American Psychologist, Vol. 41 No. 9, pp. 954-969.

McVea, J.F. (2009), "A Field Study of Entrepreneurial Decision-Making and Moral Imagination", Journal of Business Venturing, Vol. 24 No. 5, pp. 491-504.

Moberg, D.J. and Seabright, M.A. (2000), "The Development of Moral Imagination", Business Ethics Quarterly, Vol. 10 No. 4, pp. 845-884.

Roca, E. (2010), “The Exercise of Moral Imagination in Stigmatized Work Groups", Journal of Business Ethics, Vol. 96 No. 1, pp. 135-147.

Rozuel, C. (2010a), "The Sense of Self as Moral Anchor: Applying Jungian Psychology to Managers' Ethics", in Muhr, S.L., Meier Sorensen, B. and Vallentin, S. (Eds.), Ethics and Organizational Practice - Questioning the Moral Foundations of Management, Edward Elgar, Cheltenham, pp. 121-142.

Rozuel, C. (2010b), "Moral Tension in the Psyche: A Jungian Interpretation of Managers' Moral Experiences", Electronic Journal of Business Ethics and Organization Studies, Vol. 15 No. 1, pp. 36-43.

Seabright, M.A. and Schminke, M. (2002), "Immoral Imagination and Revenge in Organizations", Journal of Business Ethics, Vol. 38 No. 1/2, pp. 19-31.

Smith, A. (1790/2000), The Theory of Moral Sentiments, available at: http://www.econlib.org/library/Smith/smMS.html (accessed 3 June 2009).

Terestchenko, M. (2007), Un si Fragile Vernis d'Humanité: Banalité du Mal, Banalité du Bien, La Découverte/Poche, Paris.

Weaver, R. (1973), The Old Wise Woman, Shambhala, Boston, MA.

Werhane, P.H. (1999), Moral Imagination and Management Decision-Making, Oxford University Press, New York, NY.

Werhane, P.H. (2002), "Moral Imagination and Systems Thinking", Journal of Business Ethics, Vol.38 No.1, pp. 33-42. 